\title{
PENGARUH MOTIVASI DAN KEPUASAN KERJA TERHADAP KINERJA
}

\author{
(Studi Kasus Di Dinas Perhubungan Kabupaten Indramayu)
}

Effect of Work Motivation and Satisfaction on Performance

(Case Study at The Transportation Office of Indramayu Regency)

\author{
Yayah Khoerunnisa ${ }^{(1)}$, Nurjanah Rahayuningsih ${ }^{(2)}$, Suranta ${ }^{(3)}$ \\ nurjanahfe@unwir.ac.id; ranta.adit@gmail.com \\ Manajemen FE, Universitas Wiralodra
}

\begin{abstract}
Abstrak
Penelitian ini bertujuan untuk mengetahui adanya pengaruh Motivasi dan Kepuasan Kerja terhadap Kinerja (studi kasus di Dinas Perhubungan Kabupaten Indramayu). Data diperoleh melalui angket yang di isi oleh 58 orang pegawai Dinas Perhubungan Kabupaten Indramayu.

Total skor keseluruhan tanggapan Responden pada Variabel Kinerja dengan indikator Kualitas, Kuantitas, Jangka waktu, Penekan biaya, Pengawasan dan Hubungan antar karyawan di Dinas Perhubungan Kabupaten Indramayu adalah 2840 yang dinyatakan pada rentang skala 2370-2927, yang termasuk kategori Baik. Adapun presentase respondennya adalah $81 \%$, yang termasuk Kategori Sangat Baik. total skor keseluruhan tanggapan Responden pada Variabel Motivasi dengan indikator Semangat kerja, Kegairahan kerja, bekerjasama, bekerja efektif dan pencapaian tujuan organisasi di Dinas Perhubungan Kabupaten Indramayu adalah 2379 yang dinyatakan pada rentang skala 1975-2439, yang termasuk kategori Baik. Adapun presentase respondennya adalah $82 \%$, yang termasuk Kategori Sangat Baik.

Total skor keseluruhan tanggapan Responden pada Variabel Kepuasan Kerja dengan indikator Menyenangi pekerjaannya, Mencintai pekerjaan, Moral kerja, Kedisiplinan, Prestasi kerja di Dinas Perhubungan Kabupaten Indramayu adalah 2277 yang dinyatakan pada rentang skala 1975-2439, yang termasuk kategori Baik. Adapun presentase respondennya adalah 78,5\%, yang termasuk Kategori Baik.

Hubungan Motivasi terhadap Kinerja pada pegawai Dinas Perhubungan Kabupaten Indramayu termasuk dalam kategori Sangat Rendah. Hubungan Kepuasan Kerja terhadap Kinerja pada pegawai Dinas Perhubungan Kabupaten Indramayu termasuk dalam kategori Rendah. Hubungan Motivasi terhadap Kepuasan Kerja pada pegawai Dinas Perhubungan Kabupaten Indramayu termasuk dalam kategori Rendah.
\end{abstract}

Kata kunci: Motivasi, Kepuasan Kerja, Kinerja

\section{Abstract}

This study aims to determine the effect of motivation and job satisfaction on performance (case study in the Transportation Department of Indramayu Regency). Data was obtained through a questionnaire filled out by 58 employees of the Indramayu District Transportation Office.

The overall total score of Respondents' responses to the Performance Variables with indicators of Quality, Quantity, Duration, Cost Reduction, Supervision and Relationships among employees in the Transportation Office of Indramayu Regency is 2840 which is stated in the scale range of 2370-2927, which is included in the Good category. The percentage of respondents is $81 \%$, which is included in the Very Good Category. the overall total score of Respondents' responses to the Motivation Variable with indicators of Work enthusiasm, Excitement of work, collaboration, effective work and achievement of organizational goals in the Transportation Department of Indramayu Regency was 2379 which was stated in the 1975-2439 scale range, which included the Good category. The percentage of respondents is $82 \%$, which is included in the Very Good Category.

The overall total score of Respondents' responses to the Job Satisfaction Variable with indicators Like work, Love work, Work morale, Discipline, Job performance in the Transportation Department of Indramayu Regency is 2277 expressed in the 1975-2439 scale range, which includes the Good category. The percentage of respondents is $78.5 \%$, which includes the Good Category.

Relationship of Motivation to Performance of Indramayu Regency Transportation Department employees included in the category of Very Low. The Relationship between Job Satisfaction and Performance among Indramayu Regency Transportation Department employees is in the Low category. Relationship of Motivation to Job Satisfaction in Indramayu Regency Transportation Department employees is included in the Low category.

Keywords: Motivation, Job Satisfaction, Performance. 


\section{PENDAHULUAN}

Memperoleh kinerja pegawai yang maksimal adalah harapan semua organisasi atau instansi, salah satu hal yang bisa dilakukan oleh organisasi atau instansi harus mengetahui faktor apa saja yang menyebabkan kinerja pegawainya meningkat dan sesuai dengan tujuan organisasi atau instansi.

Sebagai salah satu lembaga pemerintah, Dinas Perhubungan Kabupaten indramayu mempunyai peranan yang strategis dalam memberikan pelayanan kepada masyarakat di wilayah Kabupaten Indramayu. Melalui tugas pokok dan fungsi-fungsinya di Dinas Perhubungan kabupaten Indramayu dan diharapkan mampu melaksanakannya dengan baik, terutama fungsi pelayanannya. Dengan demikian, efektivitas manajemen sumber daya manusia di lingkungan Dinas Perhubungn Kabupaten Indramayu perlu ditingkatkan, yakni dengan nenerapkan kinerja pegawai seoptimal mungkin.

Namun permasalahannya di Dinas Perhubungan Kabupaten Indramayu, jenjang akademik para pegawai yang tidak sesuai dengan bidangnya, kurangnya disiplin pegawai pada saat jam kerja sehingga pada saat jam kerja kantor terasa sepi, jumlah pekerjaan yang mampu diselesaikan oleh pegawai tidak tepat pada waktunya sehingga pekerjaan makin menumpuk. Kurangnya pengawasan oleh kepala dinas yang dilakukan hanya sewaktuwaktu. Dan banyaknya pegawai honor yang tidak mendapat gaji di Dinas Perhubungan tersebut.
Yayah Khoerunnisa, Nurjanah Rahayuningsih, Suranta Bukan hanya Faktor Motivasi dan Kepuasan Kerja yang dapat meningkatkan Kinerja, melainkan banyak faktor yang mempengaruhi Kinerja menurut Kasmir (2016:189), diantaranya Kemampuan dan Keahlian, Pengetahuan, Rancangan Kerja, Kepribadian, Kepemimpinan, Gaya Kepemimpinan, Budaya Organisasi, Lingkungan Kerja, Loyalitas, Komitmen dan Disiplin kerja.

\section{TINJAUAN PUSTAKA}

Menurut Robbins (dalam Kasmir, 2016:183) berpendapat:

"Kinerja adalah sebagai fungsi dari interaksi antara kemampuan atau ability (A), motivasi $(\mathrm{M})$, opportunity $(\mathrm{O})$ : yaitu kinerja $=\mathrm{f}$ (A x M x O), artinya kinerja merupakan fungsi dari kemampuan, motivasi dan kesempatan."

Kalimat diatas mengandung makna kinerja adalah merupakan fungsi dari kemampuan, maksudnya kemampuan sanggup melakukan tugas-tugas yang diberikan. Kinerja merupakan fungsi dari motivasi, maksudnya motivasi yang tinggi dari diri sendiri maupun orang lain maka akan menghasilkan kinerja yang tinggi, begitu sebaliknya. Dan kinerja merupakan fungsi dari kesempatan, masudnya jika memiliki kinerja yang baik terhadap perusahaan atau organisasi maka ada kesempatan untuk menaikkan jabatan.

Menurut Ivancevich (dalam Kasmir, 2016:183) berpendapat:

"Kinerja adalah hasil yang dicapai dari apa yang diinginkan organisasi." 
Kalimat diatas mengandung makna, kinerja adalah hasil akhir yang dicapai oleh karyawan / pegawai sesuai dengan keinginan organisasi.

Menurut Kasmir (2016:184) berpendapat:

"Kinerja adalah hasil kerja dan perilaku yang telah dicapai dalam menyelesaikan tugastugas dan tanggung jawab yang diberikan dalam suatu periode tertentu."

Kalimat diatas mengandung makna, kinerja adalah hasil kerja yang dicapai oleh pegawai dalam suatu periode tertentu.

Indikator kinerja menurut kasmir adalah:

1. Kualitas (mutu)

2. Kuantitas (jumlah)

3. Waktu (jangka waktu)

4. Penekan biaya

5. Pengawasan

6. Hubungan antar karyawan

Faktor-faktor yang mempengaruhi Kinerja.

Kasmir (2016:189), faktor-faktor yang memengaruhi kinerja baik hasil maupun perilaku kerja adalah sebagai berikut: Kemampuan dan keahlian, Pengetahuan, Rancangan kerja, Kepribadian, Motivasi kerja, Kepemimpinan, Gaya kepemimpinan, Budaya organisasi, Kepuasan kerja, Lingkungan kerja, Loyalitas, Komitmen dan Disiplin kerja.

Pengukuran Kinerja

Menurut Wibowo (2016:155) pengukuran kinerja yang tepat dapat dilakukan dengan cara:

1. Memastikan bahwa persyaratan yang diinginkan pelanggan telah terpenuhi.
Yayah Khoerunnisa, Nurjanah Rahayuningsih, Suranta

2. Mengusahakan standar kinerja untuk menciptakan perbandingan.

3. Mengusahakan jarak bagi orang untuk memonitor tingkat kinerja.

4. Menciptakan arti penting masalah kualitas dan menentukan apa yang perlu prioritas perhatian.

5. Menghindari konsekuensi dari rendahnya kualitas.

6. Mempertimbangkan penggunaan sumber daya.

7. Mengusahakan umpan balik untuk mendorong usaha perbaikan.

Manfaat Penilaian Kinerja

Menurut Allen dalam Wibowo (2016:193) menunjukan manfaat penilaian kinerja, antara lain adalah:

1. Penilaian kinerja yang dilakukan dengan berhati-hati dapat membantu memperbaiki kinerja pekerja sepanjang tahun.

2. Proses penilaian yang efektif merupakan bagian dari manajemen sumber daya manusia yang dapat membantu organisasi berhasil, dan

3. Merupakan komponen kunci dari strategi kompetitif.

Motivasi berasal dari kata motive (motif) yang berarti dorongan. Dalam motivasi setiap orang dalam melakukan suatu tindakan tertentu pasti didorong oleh adanya motif tertentu yang timbul karena adanya motif tertentu yang timbul karena adanya kebutuhan yang belum terpenuhi, tujuan yang ingin dicapai atau adanya harapan yang diinginkan. 
Motivasi kerja merupakan kombinasi kekuatan psikologis yang kompleks dalam diri masingmasing orang, sehingga setiap individu mempunyai motivasi sendiri yang mungkin berbeda-beda.

Menurut Wexley \& yukl (1977) (dalam As'ad, 2001) (dalam buku Edy Sutrisno 2017:110-111) berpendapat:

"Motivasi adalah pemberian atau penimbulan motif atau dapat pula diartikan sebagai hal atau keadaan menjadi motif. Jadi, motivasi adalah sesuatu yang menimbulkan semangat atau dorongan kerja.”

Kalimat diatas mengandung makna, motivasi adalah sesuatu yang menimbulkan semangat sehingga mau mengerjakan sesuatu.

Menurut Hasibuan (1999) (dalam Edy Sutrisno,2017:111) berpendapat:

"Motivasi adalah pemberian daya penggerak yang menciptakan kegairahan kerja seseorang, agar mereka mau bekerja sama, bekerja efektif, dan terintegrasi dengan segala daya upayanya untuk mencapai kepuasan.”

Kalimat diatas mengandung makna bahwa motivasi adalah sebagai daya penggerak seseorang agar mau melakukan sesuatu untuk mencapai kepuasan.

Menurut Robbins (dalam Hasibuan,1999) (dalam buku Edy Sutrisno, 2017:111) berpendapat:

"Motivasi sebagai suatu kerelaan berusaha seoptimal mungkin dalam pencapaian tujuan organisasi yang dipengaruhi oleh kemampuan usaha memuaskan beberapa kebutuhan individu."
Yayah Khoerunnisa, Nurjanah Rahayuningsih, Suranta

Kalimat diatas mengandung makna bahwa motivasi adalah suatu perasaan semangat dan berusaha untuk mencapai tujuan organisasi yang dipengaruhi oleh kemampuan.

Indikator motivasi yang digunkan merupakan rangkuman dari pendapat para ahli diatas adalah sebagai berikut:

1. Semangat kerja

2. Kegairahan kerja

3. Bekerjasama

4. Bekerja efektif

5. Pencapaian tujuan organisasi Faktor-faktor yang mempengaruhi Motivasi

Edy Sutrisno(2017:118), Motivasi sebagai proses psikologis dalam diri seseorang akan dipengaruhi oleh beberapa faktor, faktor-faktor tersebut dapat dibedakan atas faktor intern dan ekstrn yang berasal dari karyawan.

1. Faktor intern

Faktor intern yang dapat memengaruhi pemberian motivasi pada seseorang antara lain:

1. Keinginan untuk dapat hidup

2. Keinginan untuk dapat memiliki

3. Keinginan untuk dapat memperoleh penghargaan

4. Keinginan unuk memperoleh pengakuan

5. Keinginan untuk berkuasa

2. Faktor ekstern

1. Kondisi lingkungan kerja

2. Kompensasi yang memadai

3. Supervisi yang baik

4. Adanya jaminan pekerjaan

5. Status dan tanggung jawab 


\section{Peraturan yang fleksibel}

\section{Pemberian Motivasi}

Pemberian Motivasi kepada Pegawai merupakan kewajiban pimpinan agar pegawai dapat lebih meningkatkan produktivitas kerja. Untuk itu hal-hal yang harus diperhatikan dalam pemberian Motivasi oleh seorang pimpinan agar dapat berhasil seperti yang diharapkan menurut Edy Sutrisno (2017:144) antara lain:

1. Memahami perilaku bawahan

2. Berbuat dan berperilaku realistis.

3. Perbedaan tingkat kebutuhan

4. Mampu menggunakan keahlian

5. Pemberian motivasi harus mengacu pada orang

6. Memberikan keteladanan

Kepuasan Kerja

Kepuasan kerja pada dasarnya merupakan suatu yang bersifat individual. Setiap individu memiliki tingkat kepuasan yang berbeda-beda sesuai dengan sistem nilai yang berlaku pada dirinya. Makin tinggi penilai terhadap kegiatan dirasakan sesuai dengan keinginan individu, maka makin tinggi kepuasannya terhadap kegiatan tersebut.

Menurut Handoko (1992) dalam Edy Sutrisno (2017:75) berpendapat:

"Kepuasan kerja adalah keadaan emosional yang menyenangkan atau tidak menyenangkan bagi para karyawan memandang pekerjaan mereka. Kepuasan kerja mencerminkan perasaaan seseorang terhadap pekerjaanny. Ini tampak dalam sikap positif karyawan terhadap pekerjaan dan
Yayah Khoerunnisa, Nurjanah Rahayuningsih, Suranta segala sesuatu yang dihadapi di lingkungan kerjanya."

Kalimat diatas mengandung makna bahwa kepuasan kerja adalah perasaan seseorang terhadap pekerjaannya, sehingga dapat mempengaruhi sikapnya.

Rivai dan Sagala (2009:475) berpendapat:

"Kepuasan kerja merupakan evaluasi yang menggambarkan seseorang atas perasaan sikapnya, senang atau tidak senang, puas atau tidak puas dalam bekerja."

Kalimat diatas mengandung makna bahwa kepuasan kerja adalah perasaan senang atau tidak senang terhadap pekerjaannya.

Menurut Hasibuan (2016:202) berpendapat:

"Kepuasan kerja adalah sikap emosional yang menyenangkan dan mencintai pekerjaannya. Sikap ini dicerminkan oleh moral kerja, kedisiplinan dan prestasi kerja. Kepuasan kerja dinikmati dalam pekerjaan, luar pekerjaan dan kombinasi dalam dan luar pekerjaan."

Kalimat diatas mengandung makna bahwa kepuasan kerja adalah sikap seseorang yang mencintai pekerjaannya dan dibuktikan dengan perilaku positif terhadap pekerjaannya.

Indikator Kepuasan Kerja

Menurut Malayu S.P Hasibuan (2016:202) ada beberapa indikator kepuasan kerja sebagai berikut:

1. Menyenangi pekerjaannya

2. Mencintai pekerjaan

3. Moral kerja

4. Kedisiplinan

5. Prestasi kerja 
Faktor-faktor yang mempengaruhi Kepuasan Kerja

Menurut Gilmer (1996) dalam buku prof Edy Sutrisno (2017:77), faktor yang mempengaruhi kepuasan kerja adalah:

1. Kesempatan untuk maju.

2. Kemanan kerja.

3. Gaji.

4. Perusahaan dan manajemen.

5. Pengawasan.

6. Faktor intrinsik dari pekerjaan.

7. Kondisi kerja.

8. Aspek sosial dalam pekerjaan.

9. Komunikasi.

10. Fasilitas.

Mengukur Kepuasan Kerja

Terdapat dua macam pendekatan yang secara luas dipegunakan untuk melakukan pengukuran kepuasan kerja (Robbins, 2003:73) dalam (Wibowo,2016:422) yaitu sebagai berikut:

1. Single global rating, yaitu tidak lain dengan minta individu merespons atas suatu pertanyaan, seperti dengan mempertimbangkan semua hal, seberapa puas anda dengan pekerjaan anda? Responden menjawab antara "highly satisfied" dan "highly dissatisfied".

2. Summation score lebih canggih. Mengidentifikasi elemen kunci dalam pekerjaan dan menanyakan perasaaan pekerja tentang masing-masing elemen. Faktor spesifik yang diperhitungkan adalah: sifat pekerjaan, supervisi, upah sekarang, kesempatan promosi dan
Yayah Khoerunnisa, Nurjanah Rahayuningsih, Suranta hubungan dengan co-worker. Faktor ini di peringkat pada skala yang distandarkan dan ditambahkan untuk menciptakan job statisfaction score secara menyeluruh.

Apabila Motivasi yang dimiliki oleh seseorang itu tinggi akan mendorong Kinerja pegawai yang ditunjukkan dari kualitas, kuantitas, dan efektifitas kerjanya sehingga mencapai produktivitas yang tinggi. Sehingga dari hubungan tersebut diduga motivasi kerja memiliki pengaruh positif dan signifikan terhadap kinerja karyawan.

Motivasi berdasarkan hasil analisis menunjukkan bahwa motivasi memiliki pengaruh yang signifikan terhadap kinerja karyawan. Penelitian ini sejalan dengan hasil penelitian Dito (2010), “yang menyatakan bahwa Motivasi berpengaruh positif terhadap kinerja". Selanjutnya menurut Munandar (2001:104) “ menyatakan ada hubungan positif antara motivasi dan kinerja, artinya karyawan yang mempunyai motivasi yang tinggi cenderung mempunyai kinerja tinggi, sebaliknya mereka yang punya kinerja rendah dimungkinkan karena Motivasinya rendah".

Pengaruh Kepuasan Kerja terhadap Kinerja adalah tinggi rendahnya tingkat kepuasan kerja karyawan yang dirasakan akan mempengaruhi kinerja karyawan. Apabila kepuasan kerja tercapai maka kinerja karyawan atas organisasi tinggi.

Menurut Robbins dan judge (2007) dalam Emron, Yohny, Imas (2017:214) “ ketika data produktivitas dan kepuasan secara keseluruhan dikumpulkan untuk organisasi, kita 
menemukan bahwa organisasi yang mempunyai karyawan yang lebih puas cenderung lebih efektif bila dibandingkan organisasi yang mempunyai karyawan yang kurang puas". Dengan demikian, pegawai yang puas dalam bekerja sangat memengaruhi kinerja individu dan organisasi.

Menurut Edy Sutrisno (2017:121) dalam Teori-teori Motivasi terdapat teori kepuasan, teori ini mendasarkan pendekatannya atas faktor-faktor kebutuhan dan kepusan individu yang menyebabkannya bertidak dan berperilaku dengan cara tertentu. Teori ini memusatkan perhatian pada faktor-faktor diri orang yang menguatkan, mengarahkan, mendukung dan menghentikan perilakunya. Teori ini mencoba menjawab pertanyaan kebutuhan apa yang memuaskan dan mendorong semangat kerja seseorang. Kebutuhan dan pendorong itu adalah keinginan memenuhi kepuasan material maupun non material yang diperolehnya dari hasil pekerjaannya. Jadi kebutuhan dan kepuasannya semakin terpenuhi semangat kerjanyapuna akan semakin baik pula. Jadi pada dasarnya teori ini mengemukakan bahwa seseorang akan bertindak untuk dapat memenuhi kebutuhan dan kepuasannya. Semakin tinggi standar kebutuhan dan kepuasan yang diinginkan, semakin giat orang itu bekerja. Tinggi atau rendanhya tingkat kebutuhan dan kepuasan yang ingin dicapai seseorang mencerminkan semangat bekerja orang tersebut. Seseorang yang memiliki Motivasi yang tinggi akan menimbulkan
Yayah Khoerunnisa, Nurjanah Rahayuningsih, Suranta Kepuasan Kerjanya sehingga akan mempengaruhi kinerjnya.

Kepuasan kerja merupakan perasaan senang atau gembira atau perasaan suka seseorang sebelum dan sesudah melakukan suatu pekerjaan. Jika karyawan merasa senang atau gembira atau suka untuk bekerja maka hasil pekerjaannya pun akan berhasil baik. Demikian pula sebaliknya. Jadi dengan demikian kepuasan kerja dapat memengaruhi kinerja.

Apabila Motivasi dan Kepuasan Kerja akan ditingkatkan maka akan berpengaruh secara signifikan pada kenaikan Kinerja. Sebaliknya jika motivasi kerja dan kepuasan kerja ini tidak dikelola dan diberikan dengan baik maka juga akan berpengaruh signifikan terhadap penurunan kualitas kinerja pegawai.

\section{Kerangka Berfikir}

Menurut Kasmir (2016:184) berpendapat:

"Kinerja adalah hasil kerja dan perilaku yang telah dicapai dalam menyelesaikan tugastugas dan tanggung jawab yang diberikan dalam suatu periode tertentu."

Pegawai harus memiliki kinerja yang baik agar dapat menyelesaikan tugas dan tanggung jawabnya sesuai dengan waktu yang ditentukan. Namun ada saja pegawai yang tidak seperti itu, sehingga mengurangi kualitas Kinerjanya.

Menurut Wexley \& yukl (1977) (dalam As'ad, 2001) (dalam buku Edy Sutrisno 2017:110-111) berpendapat:

"Motivasi adalah pemberian atau penimbulan motif atau dapat pula diartikan 
sebagai hal atau keadaan menjadi motif. Jadi, motivasi adalah sesuatu yang menimbulkan semangat atau dorongan kerja."

Dengan adanya motivasi dari dalam diri sendiri maupun orang lain maka akan menimbulkan semangat kerja yang tinggi, yang akan mempengaruhi kinerjanya.

Menurut Hasibuan (2016:202) berpendapat:

"Kepuasan kerja adalah sikap emosional yang menyenangkan dan mencintai pekerjaannya. Sikap ini dicerminkan oleh moral kerja, kedisiplinan dan prestasi kerja. Kepuasan kerja dinikmati dalam pekerjaan, luar pekerjaan dan kombinasi dalam dan luar pekerjaan."

Karyawan yang tidak memperoleh kepuasan kerja tidak akan pernah mencapai kepuasan psikologis dan akhirnya akan timbul sikap atau tingkahlaku negatif dan pada gilirannya akan dapat menimbuklan frustasi, sebaliknya karyawan yang terpuaskan akan dapat bekerja dengan baik, penuh semangat, aktif dan dapat berprestasi lebih baik dari karyawan yang tidak memperoleh kepuasan kerja.

Berdasarkan kerangka berpikir di atas, maka diperoleh tiga variabel yang akan diteliti oleh peneliti, yaitu Pengaruh Motivasi (X1) dan Kepuasan Kerja (X2) terhadap Kinerja (Y). $\varepsilon$ (epsilon) adalah variabel lain yang tidak diteliti dalam penelitian. Kerangka pemikiran tersebut dapat digambarkan sebagai berikut:

\section{Hipotesis Penelitian}

Hipotesis merupakan jawaban yang masih bersifat teoritis titik tolak dalam merumuskan
Yayah Khoerunnisa, Nurjanah Rahayuningsih, Suranta hipotesis adalah dari rumusan masalah. Maka hipotesis dalam penelitian ini adalah:

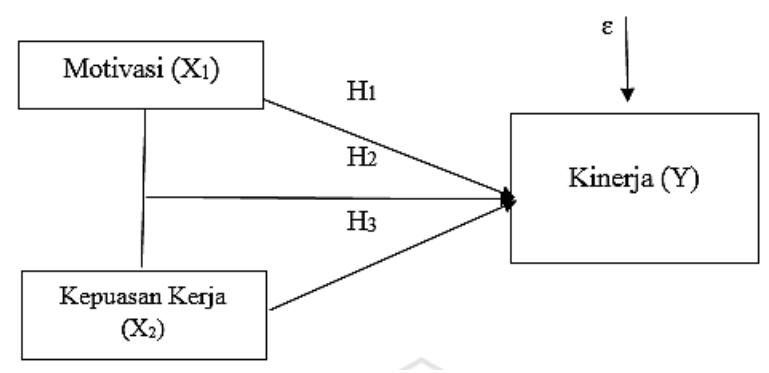

Gambar 2.2.

Hipotesis Penelitian

$\mathrm{H}_{1}$ : Diduga terdapat pengaruh Motivasi terhadap Kinerja.

$\mathrm{H}_{2}$ : Diduga terdapat pengaruh Kepuasan Kerja terhadap Kinerja.

$\mathrm{H}_{3}$ : Diduga terdapat pengaruh Motivasi dan Kepuasan Kerja terhadap Kinerja.

\section{METODE PENELITIAN}

Dalam penelitian ini, peneliti akan menggunakan suatu metode penelitian agar memudahkan peneliti untuk melakukan penelitian lebih lanjut. Metode penelitian yang digunakan adalah metode Deskriptif dan Asosiatif, metode Deskriptif suatu metode penelitian yang memberikan gambaran dan mengungkapkan suatu masalah yang terjadi pada saat penelitian berlangsung, sedangkan metode Asosiatif untuk mengetahui hubungan antara dua variabel atau lebih dalam sampel yang akan diuji.

\section{Populasi dan Sampel Penelitian}

Dalam penelitian, populasi pegawai Dinas perhubungan Kabupaten Indramayu berjumlah 69 orang Pegawai (PNS). karena jumlah populasi pegawai (tetap). Dinas perhubungan Kabupaten Indramayu berjumlah 69 Pegawai, 
pengambilan sampel menggunakan teknik sampel Acak (random sampling) yang artinya adalah pengambilan anggota sampel dari populasi dilakukan secara acak tanpa memperhatikan starata yang ada

\section{Pengujuan Validitas Kinerja}

Validitas mempunyai arti sejauh mana ketepatan dan kecermatan suatu alat ukur dalam melaksanakan fungsi ukurnya, dan kaitannya dengan tujuan pengukuran. Validitas menunjukan sejauh mana suatu alat pengukur itu mengukur apa yang ingin diukur.

Uji validitas dilakukan pada setiap butir pertanyaan di uji validitasnya. Hasil $r$ hitung dibandingkan dengan $\mathrm{r}$ tabel dimana $\mathrm{df}=\mathrm{n}-2$ dengan sig 5\%. Jika Jika $\mathrm{r}$ hitung > r tabel maka dinyatakan valid.

Berdasarkan perhitungan diperoleh:

$$
\begin{aligned}
& r_{x y}=\frac{n \sum x y-\left(\sum x\right)\left(\sum y\right)}{\sqrt{\left\{n \sum x^{2}-\left(\sum x\right)^{2}\left\{n \sum y^{2}-\left(\sum y\right)^{2}\right\}\right.}} \\
& r_{x y}=\frac{10 \cdot 2066-(43)(472)}{\sqrt{\left\{10 \cdot 189-(43)^{2}\left\{10 \cdot 22774-(472)^{2}\right\}\right.}} \\
& r_{x y}=\frac{364}{450}=0,807
\end{aligned}
$$

\begin{tabular}{|c|c|c|c|}
\hline \multirow[b]{2}{*}{$\begin{array}{c}\text { No } \\
\text { Petanyaan }\end{array}$} & \multicolumn{2}{|c|}{ Validitas } & \multirow[b]{2}{*}{ Kesimpulan } \\
\hline & $\begin{array}{l}\text { Koefisier } \\
\text { korelasi ( } \\
\text { hitung) }\end{array}$ & $\begin{array}{c}\text { Nilai kritis (r tabel } \\
\text { dengan taraf } \\
\text { signifikan } 5 \% \text { ) }\end{array}$ & \\
\hline 1. & 0,807 & 0,632 & VALID \\
\hline 2. & 0,714 & 0,632 & VALID \\
\hline 3. & 0,770 & 0,632 & VALID \\
\hline 4. & 0,825 & 0,632 & VALID \\
\hline 5. & 0,667 & 0,632 & VALID \\
\hline 6. & 0,719 & 0,632 & VALID \\
\hline 7. & 0,770 & 0,632 & VALID \\
\hline 8. & 0,706 & 0,632 & VALID \\
\hline 9. & 0,733 & 0,632 & VALID \\
\hline 10. & 0,653 & 0,632 & VALID \\
\hline 11. & 0.852 & 0.632 & VALID \\
\hline 12. & 0,792 & 0,632 & VALID \\
\hline
\end{tabular}

\section{Tabel 3.2}

\section{Uji validitas Kinerja}

Dengan $r$ tabel 0,632 indikasi 5\% dan jumlah responden 10 diperoleh data diatas, dari
Yayah Khoerunnisa, Nurjanah Rahayuningsih, Suranta tabel diatas terlihat bahwa 12 pertanyaan $\mathrm{r}$ hitung > dari $\mathrm{r}$ tabel. Jadi semua pertanyaan Valid dan dapat digunakan dalam analisa berikutnya.

\section{Perhitungan Reliabilitas Kinerja}

Menurut Sugiyono (2017: 359), pengujian reliabilitas instrumen dapat dilakukan dengan teknik belah dua dari Spearman Brown (Split half) dengan rumus sebagai berikut :

$$
r_{i}=\frac{2 r b}{1+r b}
$$

Keterangan :

$\mathbf{r}_{\mathbf{i}}=$ realibilitas internal seluruh instrument

$\mathbf{r}_{\mathbf{b}}=$ korelasi product moment antara belahan pertama dan kedua.

Kriteria ujinya adalah jika $\mathrm{r}_{\text {hitung }}$ lebih besar dari pada $r_{\text {tabel }}\left(r_{\text {hitung }}>r_{\text {tabel }}\right)$ maka instrument penelitiannya dinyatakan reliable, dan sebaliknya apabila lebih kecil dari pada $\mathrm{r}_{\text {tabel }} \quad\left(\mathrm{r}_{\text {hitung }}<\mathrm{r}_{\text {tabel }}\right)$ maka instrument penelitiannya dinyatakan tidak reliabel.

$$
\boldsymbol{r}_{i}=\frac{2 \boldsymbol{r} \boldsymbol{b}}{1+\boldsymbol{r} \boldsymbol{b}}=\frac{2 \cdot 0,994}{1+0,994}=\frac{1,988}{1,994}=
$$

$$
0,996
$$

Dari perhitungan reliabilitas angket Kinerja diperoleh $\mathrm{r}=0,996$ dengan $\mathrm{N}=10$ dan taraf signifikan 5\% didapat $\mathrm{r}$ tabel $=0,632$ sehingga $r$ hitung $>r$ tabel $(0,996>0,632)$ maka dapat disimpulkan bahwa angket Kinerja reliabel.

\section{Kisi-kisi Insrtumen Motivasi}

Instrument dalam penelitian ini memiliki validitas yang berdasarkan indikator yang disusun dan didasarkan pendapat ahli. 
Untuk mendapatkan kelayakan instrument Yayah Khoerunnisa, Nurjanah Rahayuningsih, Suranta yang digunakandalam penelitian ini yaitu: Motivasi dapat diukur melalui indikator indikator dengan pengukuran skala ordinal adalah sebagai berikut:

Dalam penelitian ini pengujian validitas menggunakan validitas kontruksi dan validitas isi. Validitas kontruksi dilakukan dengan menggunakan rumus korelasi Product Moment Pearson:

$$
r_{x y}=\frac{n \sum x y-\left(\sum x\right)\left(\sum y\right)}{\sqrt{\left\{n \sum x^{2}-\left(\sum x\right)^{2}\left\{n \sum y^{2}-\left(\sum y\right)^{2}\right\}\right.}}
$$

Keterangan :

$r_{x y}=$ Koefisien validitas

$\mathrm{n}=$ Banyaknya subjek

$\mathrm{x}=$ Nilai perbandingan

$\mathrm{y}=$ Nilai dari instrumen yang akan dicari validitasnya

Uji validitas dilakukan pada setiap butir pertanyaan di uji validitasnya. Hasil $r$ hitung dibandingkan dengan $\mathrm{r}$ tabel dimana $\mathrm{df}=\mathrm{n}-2$ dengan sig 5\%. Jika Jika $r$ hitung $>\mathrm{r}$ tabel maka dinyatakan valid.

Berdasarkan perhitungan diperoleh:

$$
\begin{aligned}
& r_{x y}=\frac{n \sum x y-\left(\sum x\right)\left(\sum y\right)}{\sqrt{\left\{n \sum x^{2}-\left(\sum x\right)^{2}\left\{n \sum y^{2}-\left(\sum y\right)^{2}\right\}\right.}} \\
& r_{x y}=\frac{10 \cdot 1218-(34)(342)}{\sqrt{\left\{10 \cdot 126-(34)^{2}\left\{10 \cdot 12394-(342)^{2}\right\}\right.}} \\
& r_{x y}=\frac{552}{851}=0,648
\end{aligned}
$$

\begin{tabular}{|c|c|c|c|c|}
\hline \multirow{2}{*}{\multicolumn{2}{|c|}{ Indikator }} & \multicolumn{2}{|c|}{ Angket } & \\
\hline & & Butir & Jumlah & \\
\hline \multicolumn{2}{|c|}{ Semangat kerja } & 1,2 & 2 & \\
\hline \multicolumn{2}{|c|}{ Kegairahan kerja } & 3,4 & 2 & \\
\hline \multicolumn{2}{|c|}{ Bekerja sama } & 5,6 & 2 & \\
\hline \multicolumn{2}{|c|}{ Bekerja efektif } & 7,8 & 2 & \\
\hline \multicolumn{2}{|c|}{$\begin{array}{l}\text { Pencapaian } \\
\text { tujuan organisasi }\end{array}$} & 9,10 & 2 & \\
\hline \multicolumn{2}{|c|}{ No Pertanyaan $\begin{array}{c}\text { Koofisien } \\
\text { korelasi(s) } \\
\text { hitusng) }\end{array}$} & \multicolumn{3}{|c|}{ 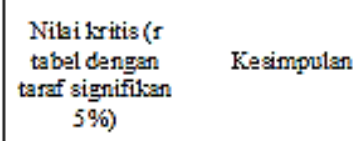 } \\
\hline 1. & 0,648 & 0,632 & & VALID \\
\hline 2. & 0,712 & 0,632 & & VALID \\
\hline$\frac{3 .}{4}$ & 0,814 & 0,632 & & $\begin{array}{l}\text { VALID } \\
\text { VAIID }\end{array}$ \\
\hline$\frac{7 .}{5 .}$ & $0,0,636$ & 0.032 & & $\begin{array}{l}\text { VALID } \\
\text { VALID }\end{array}$ \\
\hline 6. & 0,743 & 0,632 & & VALID \\
\hline 7. & 0,949 & 0,632 & & VALID \\
\hline 8. & 0,881 & 0,632 & & VALID \\
\hline 9. & 0,798 & 0,632 & & VALID \\
\hline 10. & 0,757 & 0,633 & & VALID \\
\hline
\end{tabular}

Tabel 3

\section{Uji validitas Motivasi}

Dengan $r$ tabel 0,632 indikasi 5\% dan jumlah responden 10 diperoleh data diatas, dari tabel diatas terlihat bahwa 10 pertanyaan $\mathrm{r}$ hitung > dari $\mathrm{r}$ tabel. Jadi semua pertanyaan Valid dan dapat digunakan dalam analisa berikutnya. (Lampiran hal. 130).

\section{Perhitungan Reliabilitas Motivasi}

Menurut Sugiyono (2017: 354), pengujian reliabilitas instrumen dapat dilakukan secara eksternal maupun internal. Secara eksternal pengujian dapat dilakukan dengan test-retest (stability), equivalent, dan gabungan keduanya.Secara internal reliabilitas instrumen dapat diuji dengan menganalisis konsistensi butir-butir yang ada pada instrumen dengan teknik tertentu (internal consistency).

Menurut Sugiyono (2017: 359), pengujian reliabilitas instrumen dapat 
dilakukan dengan teknik belah dua dari Spearman Brown (Split half) dengan rumus sebagai berikut:

$$
r_{i}=\frac{2 r b}{1+r b}
$$

Keterangan :

$\mathbf{r}_{\mathbf{i}}=$ realibilitas internal seluruh instrument

$\mathbf{r}_{\mathbf{b}}=$ korelasi product moment antara belahan pertama dan kedua

Kriteria ujinya adalah jika $\mathrm{r}_{\text {hitung }}$ lebih besar dari pada $\mathrm{r}_{\text {tabel }}\left(\mathrm{r}_{\text {hitung }}>\mathrm{r}_{\text {tabel }}\right)$ maka instrument penelitiannya dinyatakan reliable, dan sebaliknya apabila lebih kecil dari pada $\mathrm{r}_{\text {tabel }} \quad\left(\mathrm{r}_{\text {hitung }}<\mathrm{r}_{\text {tabel }}\right)$ maka instrument penelitiannya dinyatakan tidak reliabel.

$$
\boldsymbol{r}_{i}=\frac{2 \boldsymbol{r b}}{1+\boldsymbol{r} \boldsymbol{b}}=\frac{2 \cdot 0,988}{1+0,988}=\frac{1,976}{1,988}=0,993
$$

Dari perhitungan reliabilitas angket Kinerja diperoleh $\mathrm{r}=0,993$ dengan $\mathrm{N}=10$ dan taraf signifikan 5\% didapat $\mathrm{r}$ r tabel $=0,632$ sehingga $r$ hitung $>\mathrm{r}$ tabel $(0,993>0,632)$ maka dapat disimpulkan bahwa angket Kinerja reliabel.

\section{Kisi-kisi Instrumen Kepuasan Kerja}

Instrument dalam penelitian ini memiliki validitas yang berdasarkan indikator yang disusun dan didasarkan pendapat ahli. Untuk mendapatkan kelayakan instrument yang digunakan dalam penelitian ini yaitu: Kinerja dapat diukur melalui indikatorindikator dengan pengukuran skala ordinal adalah sebagai berikut:

Tabel 3.5

\section{Kisi-kisi Instrumen Kepuasan Kerja}

Tabel 3.6

Tabel Uji Validitas Kepuasan Kerja

\begin{tabular}{|c|c|c|c|}
\hline \multirow{2}{*}{$\begin{array}{c}\text { No } \\
\text { pertanyaan }\end{array}$} & $\begin{array}{c}|c| \\
\text { Koefisien } \\
\text { korelasi } \\
\text { (r hitung) }\end{array}$ & $\begin{array}{c}\text { Nilai } \\
\text { kritis (r } \\
\text { tabel } \\
\text { dengan } \\
\text { taraf } \\
\text { signifikan } \\
5 \%)\end{array}$ & \\
\hline 1. & 0,768 & 0,632 & Kesimpulan \\
\hline 2. & 0,697 & 0,632 & VALID \\
\hline 3. & 0,866 & 0,632 & VALID \\
\hline 4. & 0,659 & 0,632 & VALID \\
\hline 5. & 0,866 & 0,632 & VALID \\
\hline 6. & 0,737 & 0,632 & VALID \\
\hline 7. & 0,818 & 0,632 & VALID \\
\hline 8. & 0,653 & 0,632 & VALID \\
\hline 9. & 0,719 & 0,632 & VALID \\
\hline 10. & 0,644 & 0,632 & VALID \\
\hline Dengan
\end{tabular}

Dengan $r$ tabel 0,632 indikasi 5\% dan jumlah responden 10 diperoleh data diatas, dari tabel diatas terlihat bahwa 10 pertanyaan $\mathrm{r}$ hitung > dari $\mathrm{r}$ tabel. Jadi semua pertanyaan 
Valid dan dapat digunakan dalam analisa berikutnya.

\section{Perhitungan Reliabilitas Kepuasan Kerja}

Kriteria ujinya adalah jika $\mathrm{r}_{\text {hitung }}$ lebih besar dari pada $r_{\text {tabel }}\left(r_{\text {hitung }}>r_{\text {tabel }}\right)$ maka instrument penelitiannya dinyatakan reliable, dan sebaliknya apabila lebih kecil dari pada $\mathrm{r}_{\text {tabel }} \quad\left(\mathrm{r}_{\text {hitung }}<\mathrm{r}_{\text {tabel }}\right)$ maka instrument penelitiannya dinyatakan tidak reliabel.

$$
\boldsymbol{r}_{\boldsymbol{i}}=\frac{\mathbf{2 r b}}{\mathbf{1} \boldsymbol{r} \boldsymbol{r} \boldsymbol{b}}=\frac{2(0,991)}{1+0,991}=\frac{1,982}{1,981}=0,995
$$

Dari perhitungan reliabilitas angket Kinerja diperoleh $\mathrm{r}=0,995$ dengan $\mathrm{N}=10$ dan taraf signifikan 5\% didapat $\mathrm{r} r$ tabel $=0,632$ sehingga $r$ hitung $>r$ tabel $(0,995>0,632)$ maka dapat disimpulkan bahwa angket Kinerja reliabel. (Lampiran hal. 132).

\section{HASIL PENELITIAN DAN PEMBAHASAN}

\section{Karakteristik Responden}

Tabel 4.1

Karakteristik Responden berdasarkan jenis kelamin

\begin{tabular}{|c|c|c|}
\hline No & Jenis kelamin & Jumlah (orang) \\
\hline 1. & Laki-laki & 54 \\
\hline 2. & Perempuan & 4 \\
\hline \multicolumn{2}{|c|}{ Jumlah } & 58 \\
\hline
\end{tabular}

Tabel. 4.2

Karakteristik responden berdasarkan golongan

\begin{tabular}{|c|c|c|}
\hline NO & Golongan & Jumlah (orang) \\
\hline 1. & II a-c & 39 \\
\hline 2. & III a-d & 16 \\
\hline 3. & IV a-d & 3 \\
\hline & Jumlah & $\mathbf{5 8}$ \\
\hline
\end{tabular}

Yayah Khoerunnisa, Nurjanah Rahayuningsih, Suranta Analisis Deskriptif

\begin{tabular}{|c|c|c|c|c|}
\hline Variabel & Mean & Median & Modus & $\begin{array}{c}\text { Standar } \\
\text { Deviasi }\end{array}$ \\
\hline Kinerja & 48,96 & 48,83 & 48,5 & 37,92 \\
\hline Motivasi & 41,10 & 41,5 & 42,64 & 34.02 \\
\hline $\begin{array}{c}\text { Kepuasan } \\
\text { Kerja }\end{array}$ & 39,25 & 39,25 & 38,5 & 29,48 \\
\hline
\end{tabular}

\section{Kategori jumlah skor per Indikator}

\section{Motivasi, Kepuasan Kerja, Kinerja}

Hasil pengumpulan data yang diperoleh dari kuesioner kemudian dilakukan pengolahan data dan selanjutnya dilakukan analisis data. Untuk mengetahui tanggapan responden masing-masing indikator dari Variabel Motivasi, Kepuasan Kerja, dan Kinerja dilakukan analisis deskriptif. Akhirnya akan diketahui gambaran dari masing-masing variabel penelitian tersebut, yang hasilnya disajikan sebagai berikut :

Kategori jumlah skor per indikator, diperoleh melalui langkah-langkah sebagai berikut :

a. Rentang skor terendah diperoleh melalui bobot nilai paling rendah dikalikan dengan jumlah sampel, yaitu 1 x $58=58$

b. Rentang skor tertinggi diperoleh melalui bobot paling tinggi dikalikan dengan jumlah sampel, yaitu $5 \times 58=290$

c. Rentang skor per indikator diperoleh :

$$
\begin{aligned}
& R S=\frac{n(m-1)}{m} \\
& R S=\frac{58(5-1)}{5} \\
& R S=46.4=47
\end{aligned}
$$

d. Kategori skor per indikator

\section{Tabel 4.3}

Kategori Skor Per Indikator 


\begin{tabular}{|c|c|}
\hline Rentang Skor & Kategori \\
\hline $58-105$ & Sangat tidak baik \\
\hline $106-153$ & Tidak baik \\
\hline $154-201$ & Cukup baik \\
\hline $202-249$ & Baik \\
\hline $250-297$ & Sangat baik \\
\hline
\end{tabular}

Kategori Jumlah Skor Per Indikator Variabel Kinerja

Rentang skala dan kategori skor Variabel Kinerja diperoleh dengan menggunakan rumus seperti rentang skala per indikator, tetapi jumlah sampelnya dikalikan terlebih dahulu dengan jumlah indikator pada Variabel Kinerja sehingga diperoleh rentang skor dari Variabel Kinerja adalah :

a. Rentang skor terendah diperoleh dari bobot nilai paling rendah dikalikan dengan jumlah sampel dikalikan dengan jumlah pertanyaan, yaitu: 1x58x12 = 696 .

b. Rentang skor tertinggi diperoleh dari bobot nilai paling tinggi dikalikan dengan jumlah sampel dikalikan dengan jumlah pertanyaan, yaitu : 5x58x12=3480.

c. Rentang skor diperoleh :

$$
\begin{array}{r}
R S=\frac{\left(\text { n. JumlahPertanyaanVariabel } X_{1}\right)(m-1)}{m} \\
R S=\frac{(58.12)(5-1)}{5} \\
\text { RS }=556.8=557
\end{array}
$$

d. Kategori Skor Variabel Y

Tabel 4.4

Kategori Jumlah Skor Per Indikator Variabel Kinerja

\begin{tabular}{|c|c|}
\hline Rentang Skor & Kategori \\
\hline $696-1253$ & Sangat tidak baik \\
\hline $1254-1811$ & Tidak baik \\
\hline $1812-2369$ & Cukup baik \\
\hline
\end{tabular}

Yayah Khoerunnisa, Nurjanah Rahayuningsih, Suranta

\begin{tabular}{|c|c|}
\hline $2370-2927$ & Baik \\
\hline $2928-3485$ & Sangat baik \\
\hline
\end{tabular}

\section{Kategori Jumlah Skor Per Indikator Variabel Motivasi}

Rentang skala dan kategori skor Variabel Motivasi diperoleh dengan menggunakan rumus seperti rentang skala per indikator, tetapi jumlah sampelnya dikalikan terlebih dahulu dengan jumlah indikator pada Variabel Motivasi sehingga diperoleh rentang skor dari Variabel Motivasi adalah :

a. Rentang skor terendah diperoleh dari bobot nilai paling rendah dikalikan dengan jumlah sampel dikalikan dengan jumlah pertanyaan, yaitu: $1 \times 58 \times 10=580$.

b. Rentang skor tertinggi diperoleh dari bobot nilai paling tinggi dikalikan dengan jumlah sampel dikalikan dengan jumlah pertanyaan, yaitu : $5 \times 58 \times 10=2900$.

c. Rentang skor diperoleh :

$$
\begin{gathered}
R S=\frac{\left(\text { n.JumlahPertanyaanVariabel } X_{2}\right)(m-1)}{m} \\
R S=\frac{(58.10)(5-1)}{5} \\
R S=464
\end{gathered}
$$

d. Kategori Skor Variabel $\mathrm{X}_{1}$

Tabel 4.5

Kategori Jumlah Skor Per Indikator Variabel Motivasi

\begin{tabular}{|c|c|}
\hline Rentang Skor & Kategori \\
\hline $580-1044$ & Sangat tidak baik \\
\hline $1045-1509$ & Tidak baik \\
\hline $1510-1974$ & Cukup baik \\
\hline $1975-2439$ & Baik \\
\hline $2440-2904$ & Sangat baik \\
\hline
\end{tabular}




\section{Kategori Jumlah Skor Per Indikator Variabel Kepuasan Kerja}

Rentang skala dan kategori skor variabel Kepuasan Kerja diperoleh dengan menggunakan rumus seperti rentang skala per indikator, tetapi jumlah sampelnya dikalikan terlebih dahulu dengan jumlah indikator pada variabel Kepuasan Kerja sehingga diperoleh rentang skor dari variabel Kepuasan Kerja adalah :

a. Rentang skor terendah diperoleh dari bobot nilai paling rendah dikalikan dengan jumlah sampel dikalikan dengan jumlah pertanyaan, yaitu: $1 \times 58 \times 10=580$.

b. Rentang skor tertinggi diperoleh dari bobot nilai paling tinggi dikalikan dengan jumlah sampel dikalikan dengan jumlah pertanyaan, yaitu: $5 \times 58 \times 10=2900$.

c. Rentang skor diperoleh :

$$
\begin{gathered}
R S=\frac{(\text { n.JumlahPertanyaanVariabel } Y)(m-1)}{m} \\
R S=\frac{(58.10)(5-1)}{5} \\
\mathrm{RS}=464
\end{gathered}
$$

d. Kategori Skor Variabel $\mathrm{X}_{2}$

Tabel 4.6

Kategori Jumlah Skor Per Indikator Kepuasan

Kerja

\begin{tabular}{|c|c|}
\hline Rentang Skor & Kategori \\
\hline $580-1044$ & Sangat tidak baik \\
\hline $1045-1509$ & Tidak baik \\
\hline $1510-1974$ & Cukup \\
\hline $1975-2439$ & Baik \\
\hline $2440-2904$ & Sangat baik \\
\hline
\end{tabular}

\section{Deskripsi Tanggapan Responden}

Deskripsi Tanggapan Responden Terhadap

\section{Kinerja}

Yayah Khoerunnisa, Nurjanah Rahayuningsih, Suranta Tabel 4.19

Total skor penilaian Pegawai untuk Variabel Kinerja

\begin{tabular}{|c|l|c|}
\hline No & \multicolumn{1}{|c|}{ Indikator } & Total Skor \\
\hline 1 & Kualitas (mutu) & 478 \\
\hline 2 & Kuantitas (jumlah) & 477 \\
\hline 3 & Waktu (jangka waktu) & 467 \\
\hline 4 & Penekan Biaya & 465 \\
\hline 5 & Pengawasan & 479 \\
\hline 6 & Hubungan antar karyawan & 474 \\
\hline \multicolumn{2}{|c|}{ Jumlah Sumber : } & Rekapitulasi \\
\hline \multicolumn{2}{|c|}{} \\
\hline
\end{tabular}
jawaban responden Kinerja

Berdasarkan tabel diatas, total skor keseluruhan tanggapan responden Variabel Kinerja adalah 2840 yang dinyatakan pada rentang skala 2370-2927 termasuk dalam kategori Baik. Adapun presentase tanggapan responden adalah :

$$
\frac{2840}{3480} \times 100 \%=81 \%
$$

Dapat diketahui bahwa gambaran Kinerja di Dinas Perhubungan Kabupaten

Indramayu sebesar $81 \%$ termasuk dalam kategori Sangat baik.

\section{Deskripsi Tanggapan Responden Terhadap}

\section{Motivasi}

Tabel 4.30

Total skor penilaian Pegawai untuk Variabel Motivasi

\begin{tabular}{|c|l|c|}
\hline No & Indikator & Total Skor \\
\hline 1 & Semangat kerja & 459 \\
\hline 2 & Kegairahan kerja & 483 \\
\hline 3 & Bekerjasama & 483 \\
\hline 4 & Bekerja efektif & 478 \\
\hline 5 & $\begin{array}{l}\text { Pencapaian } \\
\text { tujuan organisasi }\end{array}$ & 476 \\
\hline Jumlah & \multicolumn{2}{|c|}{2379} \\
\hline
\end{tabular}


Berdasarkan tabel diatas, total skor keseluruhan tanggapan responden Variabel Motivasi adalah 2379 yang dinyatakan pada rentang skala 1975-2439 termasuk dalam kategori Baik. Adapun presentase tanggapan responden adalah :

$$
\frac{2379}{2900} \times 100 \%=82 \%
$$

Dapat diketahui bahwa gambaran Motivasi di Dinas Perhubungan Kabupaten Indramayu sebesar $82 \%$ termasuk dalam kategori Sangat Baik.

\section{Deskripsi Tanggapan Responden Terhadap} Kepuasan Kerja

Untuk mengetahui hasil tanggapan responden terhadap Variabel Kepuasan Kerja di Dinas Perhubungan Kabupaten Indramayu dengan menyebar kuesioner. Adapun hasil jawaban atas kuesioner di deskriptifkan dari masing-masing indikator terhadap Variabel Kepuasan Kerja adalah sebagai berikut :

\section{Tabel 4.41}

Total skor penilaian Pegawai untuk Variabel Kepuasan kerja

\begin{tabular}{|c|l|c|}
\hline No & Indikator & Total Skor \\
\hline 1 & $\begin{array}{l}\text { Menyenangi } \\
\text { pekerjaannya }\end{array}$ & 480 \\
\hline 2 & $\begin{array}{l}\text { Mencintai } \\
\text { pekerjaannya }\end{array}$ & 456 \\
\hline 3 & Moral kerja & 451 \\
\hline 4 & Kedisiplinan & 451 \\
\hline 5 & Prestasi kerja & 439 \\
\hline Jumlah & & 2277 \\
\hline
\end{tabular}

Sumber : Rekapitulasi jawaban responden Kepuasan kerja

Berdasarkan tabel diatas, total skor keseluruhan tanggapan responden Variabel
Yayah Khoerunnisa, Nurjanah Rahayuningsih, Suranta Kepuasan kerja adalah 2277 yang dinyatakan pada rentang skala 1975-2439 termasuk dalam kategori Baik. Adapun presentase tanggapan responden adalah :

$$
\frac{2277}{2900} \times 100 \%=78,5 \%
$$

Dapat diketahui bahwa gambaran Kepuasan kerja di Dinas Perhubungan Kabupaten Indramayu sebesar 78,5\% termasuk dalam kategori Baik.

\section{Uji Normalitas}

Untuk menguji kenormalan distribusi sampel yang dilakukan pada penelitian ini agar dapat dipertanggungjawabkan dan digunakan analisis yang tepat maka dilakukan uji normalitas terhadap data sampel yang diperoleh dari Kinerja, diuji dengan menggunakan metode Chi Kuadrat, sebagai berikut :

a. Variabel Kinerja

Berdasarkan tabel diatas diperoleh nilai chi kuadrat 10,34014 sedangkan chi kuadrat tabel dengan $\mathrm{dk}$ (deretan kebebasan) $6-1=5$. Berdasarkan tabel chi kuadrat yang ada pada tabel lampiran dapat diketahui jika $\mathrm{dk}=5$ pada tingkat salah $5 \%$ maka harga chi kuadrat tabel $(11,070)$. Karena jumlah chi kuadrat hitung 10,34014 < chi kuadrat tabel 11,070, maka distribusi sampel yang dilakukan normal.

\section{b. Variabel Motivasi}

Berdasarkan tabel diatas diperoleh nilai chi kuadrat 5,61743 sedangkan chi kuadrat tabel dengan dk (deretan kebebasan) $6-1=5$. Berdasarkan tabel chi kuadrat yang ada pada tabel lampiran dapat diketahui 
5,61743 jika $\mathrm{dk}=5$ pada tingkat salah $5 \%$ maka harga chi kuadrat tabel $(11,070)$. Karena jumlah chi kuadrat hitung 5,61743 < chi kuadrat tabel 11,070, maka distribusi sampel yang dilakukan normal.

c. Variabel Kepuasan Kerja

Berdasarkan tabel diatas diperoleh nilai chi kuadrat 10.36974 sedangkan chi kuadrat tabel dengan dk (deretan kebebasan) $6-1=5$. Berdasarkan tabel chi kuadrat yang ada pada tabel lampiran dapat diketahui 10.1381 jika dk = 5 pada tingkat salah $5 \%$ maka harga chi kuadrat tabel $(11,070)$. Karena jumlah chi kuadrat hitung 10.36974 < chi kuadrat tabel 11,070, maka distribusi sampel yang dilakukan normal.

Analisis Korelasi

Analisis Korelasi Motivasi Terhadap Kinerja

Hasil uji normalitas diatas (Chi Kuadrat) dari variabel $\mathrm{X} 1$ dan $\mathrm{Y}$, diketahui bahwa sebaran data yang diperoleh berdistribusi normal, sehingga untuk mengetahui pengaruh Motivasi terhadap Kinerja menggunakan korelasi Produk Moment Pearson.

Berdasarkan table penolong pada lampiran diketahui :

$$
\begin{array}{cr}
\Sigma X 1=2384 & \Sigma X 1^{2}=99148 \\
\Sigma X 1 Y=116861 & \\
\Sigma Y=2840 & \Sigma Y^{2}=140500
\end{array}
$$

Sebagai berikut :

$$
\begin{gathered}
r=\frac{n \sum x y-\sum x \sum y}{\sqrt{\left(n \sum x^{2}-\left(\sum x\right)^{2}\right)\left(n \sum y^{2}-\left(\sum y\right)^{2}\right)}} \\
r=\frac{(58 \times 116861)-(2384 \times 2840)}{\sqrt{\left(58 \times 99148-(2384)^{2}\right)\left(58 \times 140500-(2840)^{2}\right)}} \\
r \quad=0,098 \\
\text { r hitung }=0,098
\end{gathered}
$$

Yayah Khoerunnisa, Nurjanah Rahayuningsih, Suranta Dari perhitungan korelasi diatas dapat disimpulkan bahwa nilai $r$ hitung sebesar 0,098 termasuk kategori Sangat rendah.

\section{Analisis Korelasi Kepuasan Kerja Terhadap Kinerja}

Hasil uji normalitas diatas (Chi Kuadrat) dari variabel $\mathrm{X} 2$ dan $\mathrm{Y}$, diketahui bahwa sebaran data yang diperoleh berdistribusi normal, sehingga untuk mengetahui pengaruh Kepuasan Kerja terhadap Kinerja menggunakan korelasi Produk Moment Pearson.

Berdasarkan table penolong pada lampiran diketahui :

$$
\begin{array}{lr}
\Sigma X 2=2277 & \multicolumn{1}{c}{\Sigma X 2^{2}=} \\
90261 & \Sigma X 2 \mathrm{Y}=111756 \\
\Sigma \mathrm{Y}=2840 & \Sigma \mathrm{Y}^{2}=140500
\end{array}
$$

Sebagai berikut :

$$
\begin{gathered}
r=\frac{n \sum x y-\sum x \sum y}{\sqrt{\left(n \sum x^{2}-\left(\sum x\right)^{2}\right)\left(n \sum y^{2}-\left(\sum y\right)^{2}\right)}} \\
r=\frac{(58 \times 111756)-(2277 \times 2840)}{\sqrt{\left(58 \times 90261-(2277)^{2}\right)\left(58 \times 140500-(2840)^{2}\right)}} \\
r=0,233 \\
\quad r \text { hitung }=0,233
\end{gathered}
$$

Dari perhitungan korelasi diatas dapat disimpulkan bahwa nilai $r$ hitung sebesar 0,233 termasuk kategori Rendah.

Analisis Korelasi Motivasi Terhadap Kepuasan Kerja

Hasil uji normalitas diatas (Chi Kuadrat) dari variabel $\mathrm{X} 1$ dan $\mathrm{X} 2$, diketahui bahwa sebaran data yang diperoleh berdistribusi normal, sehingga untuk mengetahui pengaruh Motivasi terhadap Kepuasan Kerja menggunakan korelasi Produk Moment Pearson. 
Berdasarkan table penolong pada lampiran diketahui :

$$
\begin{array}{lr}
\Sigma X 1=2384 \quad \Sigma X 1^{2}=99148 \\
\quad \Sigma X 1 X 2=93963 & \\
\Sigma X 2=2277 & \Sigma X 2^{2}= \\
90261 &
\end{array}
$$

Sebagai berikut :

$$
\begin{gathered}
r=\frac{n \sum x 1 \times 2-\sum x 1 \sum x 2}{\sqrt{\left(n \sum x 1^{2}-\left(\sum x 1\right)^{2}\right)\left(n \sum x 2^{2}-\left(\sum x 2\right)^{2}\right)}} \\
r=\frac{(58 \times 93963)-(2384 \times 2277)}{\sqrt{\left(58 \times 99148-(2384)^{2}\right)-\left(58 \times 90261-(2277)^{2}\right)}} \\
\mathrm{r}=0,369 \\
\mathrm{r} \text { hitung }=0,369
\end{gathered}
$$

Dari perhitungan korelasi diatas dapat disimpulkan bahwa nilai rhitung sebesar

\section{0,369 termasuk kategori Rendah.}

\section{Analisis Koefisien Korelasi Berganda}

Korelasi ganda merupakan angka yang menunjukan arah dan kuatnya hubungan antara dua variabel independen secara bersama-sama atau lebih dari satu variabel independen. Jadi analisis korelasi ganda bertujuan untuk mengetahui koefisien korelasi antara variabel Motivasi(X1) dan Kepuasan $\operatorname{Kerja}(\mathrm{X} 2)$ terhadap $\operatorname{Kinerja(Y)}$ secara simultan atau bersama-sama.

Rumus yang digunakan sebagai berikut :

$$
\begin{gathered}
R y x 1 \times 2 \\
=\frac{\sqrt{r y x 1^{2}+r y x 2^{2}-2 r y x 1 \cdot r y x 2 \cdot r x 1 \times 2}}{1-r x 1 \times 2^{2}} \\
R y x 1 \times 2=\sqrt{\frac{(0,098)^{2}+(0,233)^{2}-2 \cdot(0,098) \cdot(0,233) \cdot(0,369)}{1-(0,369)^{2}}} \\
R y x 1 x 2=\sqrt{\frac{0,04694}{0,836}} \\
=0,233
\end{gathered}
$$

Dari hasil perhitungan diatas diperoleh koefisien korelasi sebesar 0,233 yang termasuk
Yayah Khoerunnisa, Nurjanah Rahayuningsih, Suranta kategori Rendah. Dapat disimpulkan bahwa pengaruh Motivasi dan Kepuasan Kerja terhadap Kinerja adalah searah dan positif.

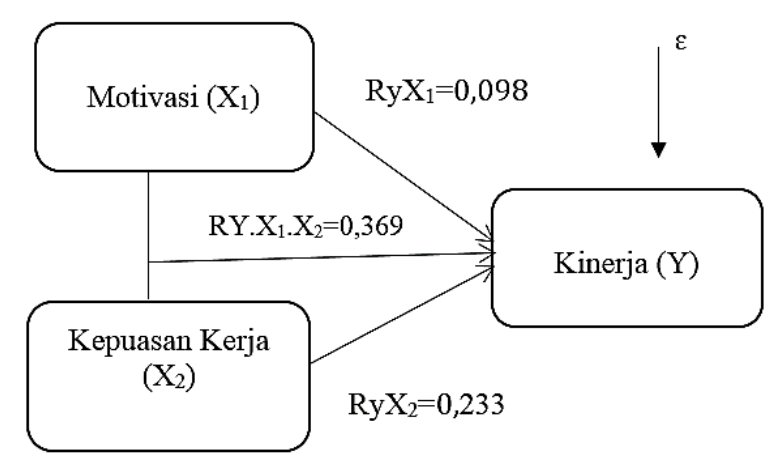

Gambar 4.5

Analisis Penelitian

\section{Analisis Koefisien Determinasi}

Koefisien determinasi merupakan suatu ukuran yang menunjukan besar sumbangan dari variabel penjelas terhadap variabel respon. Dengan kata lain, koefisien determinasi menunjukan variasi naik turunnya $\mathrm{Y}$ yang diterangkan oleh pengaruh linear X.

Analisis Koefisien Determinasi Motivasi Terhadap Kinerja

Untuk mengetahui seberapa besar kontribusi Motivasi terhadap Kinerja, maka digunakan rumus koefisien determinasi sebagai berikut :

Analisis koefisien determinasi X1 terhadap Y

$$
\begin{aligned}
& \mathrm{Kd}=\mathrm{r}^{2} \times 100 \% \\
& \mathrm{Kd}=(0,098)^{2} \times 100 \% \\
& \mathrm{Kd}=0,960 \%
\end{aligned}
$$

Artinya Motivasi memberikan pengaruh terhadap Kinerja di Dinas Perhubungan Kabupaten Indramayu sebesar 0,960\%, 
sedangkan sisanya yang 99,03\% dipengaruhi oleh faktor-faktor lain yang tidak diteliti.

Analisis Koefisien Determinasi Kepuasan Kerja Terhadap Kinerja

Analisis koefisien determinasi X2 terhadap Y

$$
\begin{aligned}
& \mathrm{Kd}=\mathrm{r}^{2} \times 100 \% \\
& \mathrm{Kd}=(0,233)^{2} \times 100 \% \\
& \mathrm{Kd}=5,428 \%
\end{aligned}
$$

Artinya Motivasi memberikan pengaruh terhadap Kepuasan Kerja di Dinas Perhubungan Kabupaten Indramayu sebesar $5,428 \%$ sedangkan sisanya yang $94,5 \%$ dipengaruhi oleh faktor-faktor lain yang tidak diteliti.

Analisis Koefisien Determinasi Motivasi dan Kepuasan Kerja Terhadap Kinerja

Analisis koefisien determinasi X1, X2 terhadap Y

$$
\begin{aligned}
& \mathrm{Kd}=\mathrm{r}^{2} \times 100 \% \\
& \mathrm{Kd}=(0,369)^{2} \times 100 \% \\
& \mathrm{Kd}=13,6 \%
\end{aligned}
$$

Artinya Motivasi dan Kepuasan Kerja memberikan pengaruh terhadap Kinerja di Dinas Perhubungan Kabupaten Indramayu sebesar $13,6 \%$ sedangkan sisanya yang $86,3 \%$ dipengaruhi oleh faktor-faktor lain yang tidak diteliti.

\section{KESIMPULAN DAN SARAN \\ Kesimpulan}

Berdasarkan penelitian mengenai Pengaruh Motivasi dan Kepuasan Kerja Terhadap Kinerja studi kasus di Dinas Perhubungan Kabupaten Indramayu, maka dapat ditarik kesimpulan sebagai berikut:
Yayah Khoerunnisa, Nurjanah Rahayuningsih, Suranta

1. Berdasarkan total skor keseluruhan tanggapan Responden pada Variabel Kinerja dengan indikator Kualitas, Kuantitas, Jangka waktu, Penekan biaya, Pengawasan dan Hubungan antar karyawan di Dinas Perhubungan Kabupaten Indramayu adalah 2840 yang dinyatakan pada rentang skala 2370-2927, yang termasuk kategori Baik. Adapun presentase respondennya adalah $81 \%$, yang termasuk Kategori Sangat Baik.

2. Berdasarkan total skor keseluruhan tanggapan Responden pada Variabel Motivasi dengan indikator Semangat kerja, Kegairahan kerja, bekerjasama, bekerja efektif dan pencapaian tujuan organisasi di Dinas Perhubungan Kabupaten Indramayu adalah 2379 yang dinyatakan pada rentang skala 1975-2439, yang termasuk kategori Baik. Adapun presentase respondennya adalah $82 \%$, yang termasuk Kategori Sangat Baik.

3. Berdasarkan total skor keseluruhan tanggapan Responden pada Variabel Kepuasan Kerja dengan indikator Menyenangi pekerjaannya, Mencintai pekerjaan, Moral kerja, Kedisiplinan, Prestasi kerja di Dinas Perhubungan Kabupaten Indramayu adalah 2277 yang dinyatakan pada rentang skala 1975-2439, yang termasuk kategori Baik. Adapun presentase respondennya adalah 78,5\%, yang termasuk Kategori Baik.

4. Hubungan Motivasi terhadap Kinerja pada pegawai Dinas Perhubungan Kabupaten 
Indramayu termasuk dalam kategori Sangat Rendah. Dilihat dari hasil analisis korelasi Motivasi terhadap Kinerja yaitu 0,098, dengan adanya pengaruh Motivasi terhadap Kinerja dilihat dari hasil koefisisen Determinasi sebesar 0,960\% sedangkan sisanya 99,03\% di pengaruhi oleh faktor-faktor lain yang tidak diteliti.

5. Hubungan Kepuasan Kerja terhadap Kinerja pada pegawai Dinas Perhubungan Kabupaten Indramayu termasuk dalam kategori Rendah. Dilihat dari hasil analisis korelasi Kepuasan Kerja terhadap Kinerja yaitu 0,233 , dengan adanya pengaruh Kepuasan Kerja terhadap Kinerja dilihat dari hasil koefisisen Determinasi sebesar $5,428 \%$ sedangkan sisanya $94,5 \%$ di pengaruhi oleh faktor-faktor lain yang tidak diteliti.

6. Hubungan Motivasi terhadap Kepuasan Kerja pada pegawai Dinas Perhubungan Kabupaten Indramayu termasuk dalam kategori Rendah. Dilihat dari hasil analisis korelasi Motivasi terhadap Kepuasan Kerja yaitu 0,369, dengan adanya pengaruh Motivasi terhadap Kepuasan Kerja dilihat dari hasil koefisisen Determinasi sebesar 13,6\% sedangkan sisanya $86,3 \%$ di pengaruhi oleh faktorfaktor lain yang tidak diteliti.

\section{DAFTAR PUSTAKA}

Edison, Emron, Yohny Anwar, Imas Komariyah. 2017. Manajemen Sumber Daya Manusia. Bandung: Alfabeta.
Yayah Khoerunnisa, Nurjanah Rahayuningsih, Suranta Hasibuan,Malayu S.P.2016. Manajemen Sumber Daya Manusia. Jakarta: PT. Bumi Aksara.

Kasmir. 2016. Manajemen Sumber Daya Manusia. Jakarta: PT. Rajagrafindo Persada.

Sugiono.2017. Metode penelitian Kuantitatif, Kualitatif, dan R\&D. Bandung: Alfabeta. Sutrisno, Edy.2017. Manajemen Sumber Daya Manusia. Jakarta: Kencana.

Wibowo. 2016. Manajemen Kinerja. Jakarta: PT. Raja Grafindo Persada.

Dewi, Chadek N.C, I Wayan Bagia, Gede Putu A.J.S. (2014). Pengaruh Stres Kerja dan Kepuasan Kerja terhadap Kinerja Karyawan pada bagian tenaga penjualan UD Surya Raditya Negara. Dalam ejurnal Bisma Universitas Pendidikan Ganesha. Vol.2.

H.R, Sumardi.(2017). Pengaruh Kompensasi, Pemberdayaan dan Kepuasan Kerja terhadap Kinerja dosen di Universitas Wiralodra indramayu. Dalam Gema Wiralodra. Vol.8 .No.2.

Latumantow, Rudi Yobie, Bernhard tewal, Victor P lengkong. (2015). Pengaruh Motivasi dan Kepuasan Kerja terhadap Kinerja Karyawan dimoderasi oleh masa kerja pada PT.Deho caming company Bitung. Dalam Jurnah EMBA. Vol. 3. No.1.

Potu, Aurelia. (2013). Kepemimpinan, Motivasi dan Lingkungsn kerja pengaruhnya terhadap kinerja karyawan pada Kanwil Ditjen Kekayaan Negara 
Suluttenggo dan Maluku Utara di

Yayah Khoerunnisa, Nurjanah Rahayuningsih, Suranta Manado. Dalam jurnal EMBA. Vol 9. No.4.

Ramadhita, Sinta, Hadi setiawan, Nurul Ummi. (2017). Pengaruh Motivasi dan Kepuasan Kerja terhadap Kinerja studi kasus Dinas Koperasi dan UMKM Provinsi Banten. Jurnal Tekhnik Industri. Vol.5. No.1.

Yudha, Redi Indra. (2018). Pengaruh Budaya Organisasi dan Kepuasan Kerja terhadap Kinerja Karyawan pada PT. Jaya Abadi Sumber Pasifik Kota Jambi. Dalam jurnal Manajemen dan Kewirausahaan. Vol. 9 No. 2. 